Ami no Ami de Organocat al yst s for Asymmet ri c $M$ chael Addi ti on of $\beta$ - Keto Esters wi th $\beta$

- N trool efins

\begin{tabular}{|l|l|}
\hline 著者 & $\begin{array}{l}\text { ONOLABI I si aka Al ade, CHENAPURAM Nadhu, SEK } \\
\text { Chi gusa, OKUYAMA Yuko, KWON Eunsang, UMAl } \\
\text { Koj i , TOK WA M chi o, TAKESH TA M t suhi ro, } \\
\text { NAKANO H r ot o }\end{array}$ \\
\hline $\begin{array}{l}\text { j our nal or } \\
\text { publ i cat i on } \mathrm{t} \text { i t l e }\end{array}$ & Bul I et i $\mathrm{n}$ of the Chemi cal Soci et y of Japan \\
\hline vol une & 92 \\
\hline nunber & 3 \\
\hline page r ange & $696-701$ \\
\hline year & 2019 \\
\hline URL & ht t p: //hdl . handl e. net $/ 10258 / 00009895$ \\
\hline
\end{tabular}




\title{
Amino Amide Organocatalysts for Asymmetric Michael Addition of $\beta$-Keto Esters with $\beta$-Nitroolefins
}

\author{
Isiaka Alade Owolabi, ${ }^{1}$ Madhu Chennapuram, ${ }^{1}$ Chigusa Seki, ${ }^{1}$ Yuko Okuyama, ${ }^{2}$ Eunsang Kwon, ${ }^{* 3}$ Koji Uwai, \\ Michio Tokiwa, ${ }^{4}$ Mitsuhiro Takeshita, ${ }^{4}$ and Hiroto Nakano ${ }^{* 1}$ \\ ${ }^{1}$ Division of Sustainable and Environmental Engineering, Graduate School of Engineering, Muroran Institute of Technology, 27-1 \\ Mizumoto, Muroran 050-8585, Japan. \\ ${ }^{2}$ Tohoku Medical and Pharmaceutical University, 4-4-1 Komatsushima, Aoba-Ku, Sendai 981-8558, Japan \\ ${ }^{3}$ Research and Analytical Center for Giant Molecules, Graduate School of Sciences, Tohoku University, 6-3 Aoba, Aramaki, Aoba-Ku, \\ Sendai 980-8578, Japan, E-mail: ekwon@m.tohoku.ac.jp \\ ${ }^{4}$ Tokiwakai Group, 62 Numajiri Tsuduri-chou Uchigo Iwaki 973-8053, Japan \\ E-mail: catanaka@mmm.muroran-it.ac.jp
}

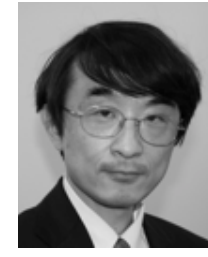

Hiroto Nakano

Dr. Hiroto Nakano received his Ph.D. degree in 1989 from Tohoku Pharmaceutical University (at present: Tohoku Medical and Pharmaceutical University). He joined the faculty of this university, as an assistant professor and then an associate professor. During the period of 1997 to 1999, he also joined Professor Albert I. Meyers group at Colorado State University in USA as a Postdoc. From 2010, he is a professor of Muroran Institute of Technology. His research interest is catalytic asymmetric syntheses in the field of synthetic organic chemistry.

\begin{abstract}
Asymmetric Michael addition of $\beta$-keto esters with trans- $\beta$-nitroolefins using chiral amino amide organocatalyst was tried and afforded synthetically useful chiral Michael adducts in both excellent chemical yields (up to $99 \%$ ) and stereoselectivities (up to $d r$. 99:1, up to $98 \%$ ee).
\end{abstract}

Keywords: Amino amide, Organocatalyst, Michael addition

\section{Introduction}

The Michael addition is widely recognized as one of the most general and versatile method for the formation of carbon-carbon bonds in the field of synthetic organic chemistry. ${ }^{1}$ Especially, the reaction of tri-substituted carbon nucleophiles and electron-deficient olefins to form the chiral Michael adducts containing adjacent quaternary and tertiary stereocenters, which are the valuable chiral building blocks for many synthetic intermediates and biologically active natural products. $^{2}$ For this reaction, several efficient chiral organometallic catalysts and organocatalysts have been investigated in recent years. ${ }^{3}$ For examples, chiral bifunctional $\mathrm{Co}_{2}$-schiff based binaphthyl type organometallic catalyst and both thiourea- and squaramide type organocatalysts have been reported to achieve high levels of stereoselectivities. ${ }^{4,5}$ However, there are still need to develop more efficient and environmentally catalysts, especially, organocatalysts that will enhance high stereoselectivities for this reaction.

In the last decade, our research group has been extensively exploring a series of novel multifunctional amino alcohol based organocatalysts and its derivatives for asymmetric reactions. ${ }^{6}$

Most recently, we reported that a polycyclic aromatic substituted primary amino amide type organocatalyst $\mathbf{X}$ for the enantioselective crossed aldol reaction of ketones with isatins or aromatic aldehydes. ${ }^{7,8}$ This catalyst $\mathbf{X}$ has the basic primary amino group for the enamine formation and hydrogen bonding sites, and also the amide group for hydrogen bonding site to the substrate. In addition, the bulky flexible polycyclic aromatic ring on the nitrogen atom of amide group in catalyst might be shielded effectively the one enantiotopic face on the basis of a steric factor to enhance the selectivity (Scheme 1).,

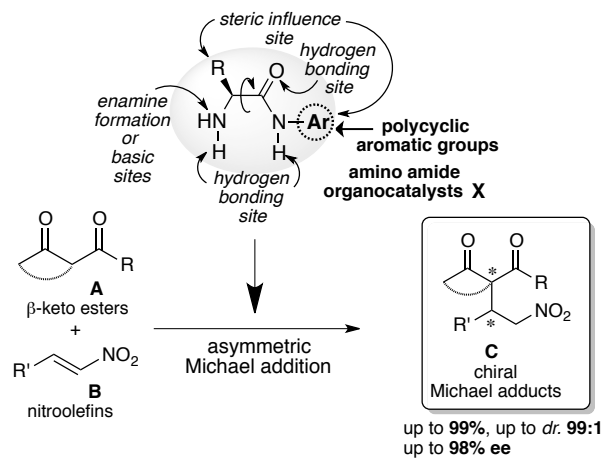

Scheme 1. Catalyst's concept and its use in Michael addition.

Herein, we describe that our explored amino amide organocatalyst $\mathbf{X}$ showed a highly efficient catalytic activity in asymmetric Michael addition of $\beta$-keto esters $\mathbf{A}$ with various nitroolefins $\mathbf{B}$ to afford the corresponding chiral Michael adducts $\mathbf{C}$ in good to excellent chemical yields and stereoselectivities (up to $99 \%$, up to $d r$. 99:1, up to $98 \% e e$ ), in the presence of eco-friendly aqueous medium (Scheme 1).

\subsection{General}

\section{Experimental}

Unless otherwise noted, the commercial reagents were used without purification. All reactions were carried out using flamed-dried glassware. Thin layer chromatography (TLC) was performed on silica gel $60 \mathrm{~F}_{254}$ and analytes were detected by UV light and by staining with ninhydrin solution. The flash column chromatography was performed on silica gel $60 \mathrm{~N}$ $(40-50 \mu \mathrm{m})$. NMR spectra were measured on JEOL 
JNM-ECA-500 MHz spectrometer. ${ }^{1} \mathrm{H}$ NMR spectra referred to the TMS $(\delta=0.00 \mathrm{ppm}) .{ }^{13} \mathrm{C}$ NMR $(125 \mathrm{MHz})$ referred to the residual solvent $(\delta=77.6 \mathrm{ppm})$ were measured in $\mathrm{CDCl}_{3}$. IR spectra measured using JASCO-4100 spectrophotometer. Optical rotations values were obtained using JASCO DIP-360 digital polarimeter. High-resolution mass spectra (HRM) were measured by EI mode using Hitachi RMG-6MG and JEOL-JNM-DX303 spectrometers. The enantiomeric excess was obtained by using chiral HPLC using a Chiralcel OD-H column.

2.1.1. General procedure for the synthesis of catalysts $(4 \mathrm{~h}, \mathrm{i})$.

To a vial contain amine $2 \mathbf{d}(0.36 \mathrm{mmol})$ and $N$-Boc amino acids $\mathbf{1 b}, \mathbf{c}(0.30 \mathrm{mmol})$ were added 1-hydroxybenzotriazole (HOBt) (49 mg, $0.36 \quad \mathrm{mmol}) \quad$ and 1-(3-dimethylaminopropyl)-3-ethylcarbondiimide (EDC) (64 $\mu \mathrm{L}, 0.36 \mathrm{mmol})(\mathrm{EDC})$ in $\mathrm{CH}_{2} \mathrm{Cl}_{2}(3 \mathrm{~mL})$ and the mixtures was stirred at $0{ }^{\circ} \mathrm{C}$ for $1 \mathrm{~h}$. Subsequently, the reaction mixture was stirred for $20 \mathrm{~h}$. The crude reaction mixture was washed with EtOAc, $0.1 \mathrm{~N} \mathrm{HCl}$, saturated $\mathrm{NaHCO}_{3}$ solution and brine. The organic layer was dried over anhydrous $\mathrm{Na}_{2} \mathrm{SO}_{4}$ and evaporated under a reduced pressure. The residue was dissolved in dry $\mathrm{CH}_{2} \mathrm{Cl}_{2}(1 \mathrm{~mL})$ and $\mathrm{CF}_{3} \mathrm{CO}_{2} \mathrm{H}(0.4 \mathrm{~mL})$ was added at $0{ }^{\circ} \mathrm{C}$. The reaction temperature was increased to r.t. and stirred for $3 \mathrm{~h}$. Upon the completion of the reaction (monitored by TLC) in detail follow (Scheme 2). The residue $4 \mathbf{h}, \mathbf{i}$ were purified by flash column chromatography on $\mathrm{SiO}_{2}$ (EtOAc/hexane = $3 / 1){ }^{7,8}$

\subsection{The synthesis of the catalysts $4 a-i$}

The organocatalysts $\mathbf{4 a - g}$ analytical data have been reported in our recent works. ${ }^{7,8}$

\subsection{1. (S)-2-Amino- $N$-(naphthalene-1-yl)-2-phenylethana- mide (4h)}

Brown oil, 74\% yield. $[\alpha]_{\mathrm{D}}^{22}=-36.00\left(\mathrm{c}=0.200, \mathrm{CH}_{2} \mathrm{Cl}_{2}\right)$. IR (neat) $3288,1681,1526,947,858,770,696, \mathrm{~cm}^{-1} .{ }^{1} \mathrm{H}$ NMR $\left(500 \mathrm{MHz}, \mathrm{CDCl}_{3}\right): \delta=10.20($ br s, $1 \mathrm{H}, \mathrm{NH}), 8.23-8.22(\mathrm{~d}, J=$ $7.0 \mathrm{~Hz}, 1 \mathrm{H}), 7.91-7.86(\mathrm{~m}, 2 \mathrm{H}), 7.66-7.64(\mathrm{~d}, J=8.0 \mathrm{~Hz}, 1 \mathrm{H})$, 7.56-7.25 (m, 8H), 2.05 (br s, $2 \mathrm{H}, \mathrm{NH}_{2}$ ), 1.14-1.13 (d, $J=6.0$ $\mathrm{Hz}, 1 \mathrm{H}) .{ }^{13} \mathrm{C}$ NMR $\left(125 \mathrm{MHz}, \mathrm{CDCl}_{3}\right): \delta=171.83,141.02$, $134.16,132,48,129.02,128.92,128.26,127.12,126.37,126.09$, 126.03, 125.14, 120.57, 118.81, 77.69, 77.43, 77.18, 60.67. MS (EI): $\mathrm{m} / \mathrm{z}=276[\mathrm{M}+\mathrm{H}]^{+}$. HRMS (EI): calcd. for $\mathrm{C}_{18} \mathrm{H}_{16} \mathrm{~N}_{2} \mathrm{O}$ $[\mathrm{M}+\mathrm{H}]^{+}$276.1263, found 276.1263.

\subsection{2. (S)-2-Amino- $N$-(naphthalene-1-yl)-3-phenylpropan- amide (4i)}

Brown oil, $59 \%$ yield. $[\alpha]_{\mathrm{D}}{ }^{20}=-17.34\left(\mathrm{c}=0.64, \mathrm{CH}_{2} \mathrm{Cl}_{2}\right)$. IR (neat) $3295,2920,1677,1524,1250,771,699 \mathrm{~cm}^{-1} .{ }^{1} \mathrm{H}$ NMR $\left(500 \mathrm{MHz}, \mathrm{CDCl}_{3}\right): \delta=10.21($ br s, $1 \mathrm{H}, \mathrm{NH}), 8.26-8.25(\mathrm{~d}, J=$ $7.0 \mathrm{~Hz}, 1 \mathrm{H}), 7.87-7.85(\mathrm{~m}, 1 \mathrm{H}), 7.66-7.64(\mathrm{t}, J=9.5 \mathrm{~Hz}, J=5.0$ $\mathrm{Hz} 1 \mathrm{H}), 7.67-7.65(\mathrm{~d}, J=8.5 \mathrm{~Hz}, 1 \mathrm{H}), 7.52-7.25(\mathrm{~m}, 8 \mathrm{H}), 3.91$ (m, 1H), 3.47-3.43 (dd, $J=13.5 \mathrm{~Hz}, J=10.0 \mathrm{~Hz} 1 \mathrm{H}), 2.94-2.89$ (m, 1H), 1.65 (br s, 2H, $\left.\mathrm{NH}_{2}\right) .{ }^{13} \mathrm{C}$ NMR (125 MHz, $\left.\mathrm{CDCl}_{3}\right): \delta$ $=172.96,137.81,134.19,132.60,129.53,128.98,128.87$, $127.09,126.47,126.27,126.09,125.04,120.65,118.69,77.69$, 77.45, 77.19, 57.21, 40.89. MS (EI): $\mathrm{m} / \mathrm{z}=290[\mathrm{M}+\mathrm{H}]^{+}$. HRMS (EI): calcd. for $\mathrm{C}_{19} \mathrm{H}_{18} \mathrm{~N}_{2} \mathrm{O}[\mathrm{M}+\mathrm{H}]^{+}$290.1419, found 290.1418 .

\subsection{General procedure for the asymmetric Michael addition of $\beta$-keto esters to trans- $\beta$-nitroolefins}

To a stirred solution of trans- $\beta$-nitroolefins $\mathbf{6 a - h}(0.34 \mathrm{mmol}$, $50.00 \mathrm{mg})$ and organocatalysts $4 \mathbf{a}-\mathbf{i}(0.03 \mathrm{mmol}, 10 \mathrm{~mol} \%)$ in $\mathrm{H}_{2} \mathrm{O}(0.5 \mathrm{~mL})$ were added $\beta$-keto esters 5a-e $(0.67 \mathrm{mmol}, 0.08$
$\mathrm{mL}$ ) at room temperature (r.t.). The crude reaction mixture was stirred at r.t. until the reaction completed been monitored by TLC. Afterwards, the mixture was extracted with $\mathrm{CH}_{2} \mathrm{Cl}_{2}(3 \times 5$ $\mathrm{mL}$ ), and the organic layer was dried over anhydrous $\mathrm{Na}_{2} \mathrm{SO}_{4}$, filtered, and concentrated under a reduced pressure. The residue was purified by flash column chromatography on $\mathrm{SiO}_{2}$ (EtOAc/hexane $=10 / 1)$ to afford the corresponding chiral Michael adducts $\mathbf{7 a - 1}$. The diastereomeric ratio was determined by the ${ }^{1} \mathrm{H}$ NMR analysis of the crude product. The compounds 7a-l were known compounds and were identified in accordance with the previously reported methods. ${ }^{9}$

\section{Results and Discussion}

For an amino amide with polycyclic aromatic ring organocatalysts for this reaction, amino amides having 1- or 4-pyrenyl 4a-d, 1-anthracenyl 4e, and 1-naphthyl 4f-i groups were selected (Scheme 2). The catalysts 4a-g showed good catalytic activities in the aldol reactions using isatins and general ketones such as cyclohexanone, respectively, in our previous reports. ${ }^{7,8}$ The catalysts $\mathbf{4 a - i}$ were easily prepared by the condensations of the corresponding chiral $N$-Boc amino acids 1a-d with polycyclic aromatic amines $\mathbf{2 a - d}$, according to our previous methods. ${ }^{7,8}$

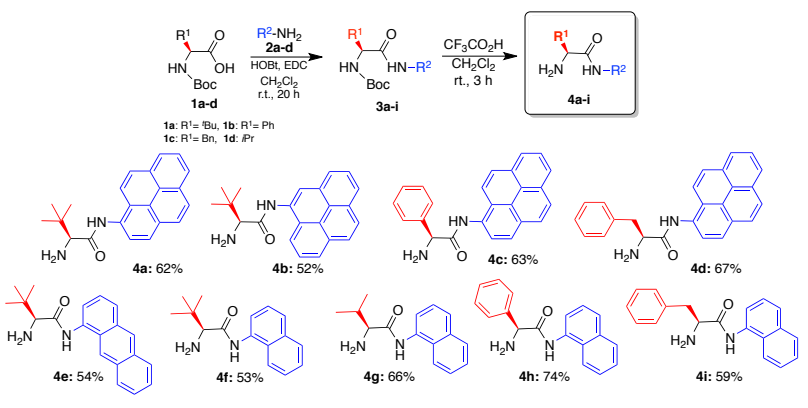

Scheme 2. Synthesis of amino amide organocatalysts 4 a-i.

First, we carried out the Michael addition of methyl2-oxo-cyclopentanecarboxylate 5a and trans- $\beta$-nitroolefin $\mathbf{6 a}$ with $10 \mathrm{~mol} \%$ of our explored bulkiest organocatalysts 4 a-d having pyrenyl groups in the presence of $\mathrm{H}_{2} \mathrm{O}$ at room temperature (Table 1), according to our previous reported aldol

Table 1. Asymmetric Michael additions of $\beta$-keto esters 5a with trans- $\beta$-nitroolefin $\mathbf{6 a}$ using organocatalysts $\mathbf{4 a - i}$.

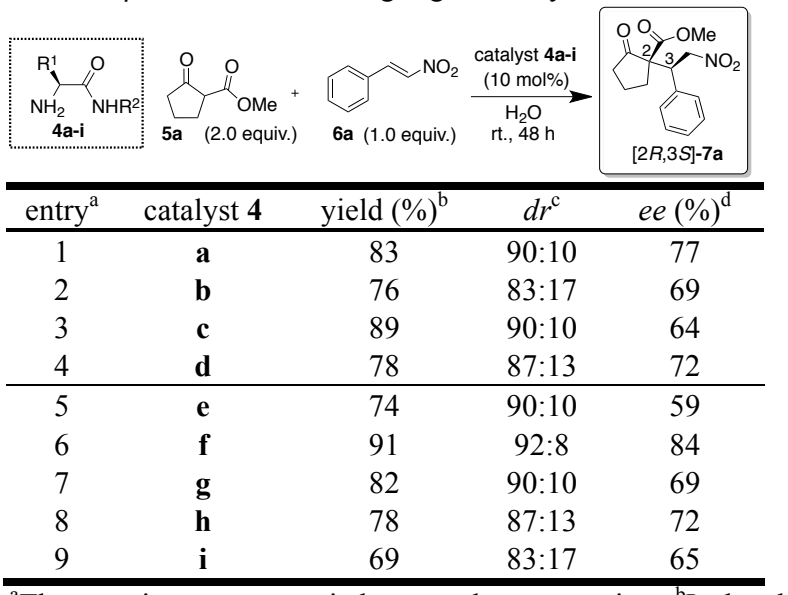

${ }^{\mathrm{a}}$ The reactions were carried out under suspension. ${ }^{\mathrm{b}}$ Isolated yields. ${ }^{\mathrm{c}}$ The diastereomeric ratio $(d r)$ was determined by ${ }^{1} \mathrm{H}$ NMR spectroscopy of the crude reaction mixture. ${ }^{\mathrm{d}}$ The ee values were determined by HPLC with a Daicel Chiralcel OD-H column. 
reaction conditions. ${ }^{8}$ All catalysts 4a-d showed catalytic activities in this reaction and afforded the chiral Michael adduct 7a as the main product with moderate to good chemical yields and stereoselectivities, (up to $89 \%$, up to $d r$. $90: 10$, up to $77 \%$ ee). Especially, tert-butyl-catalyst 4a with 1-pyrenyl group afforded the adduct $\mathbf{7 a}$ in good chemical yield and stereoselectivities $(83 \%, d r .90: 10,77 \%$ ee, entry 1). Furthermore, the same reaction using bulkier catalyst $4 \mathbf{e}$ with the 1-anthracenyl group also gave the adduct $7 \mathbf{a}$ in good chemical yield and moderate stereoselectivities (74\%, $d r$. 90:10, $59 \%$ ee, entry 5). Moreover, the reaction using less bulky tert-butyl-catalyst $\mathbf{4 f}$ with 1-naphthyl group was also examined and the best result $(91 \%, d r .92: 8,84 \%$ ee, entry 6) was obtained by using this catalyst. The determination of absolute configuration and stereoselectivity of $7 \mathbf{a}$ were confirmed on comparison with the previous data.

In order to optimize the reaction conditions using the superior catalyst $\mathbf{4 f}$ (Table 2), we next examined the molar ratio of the catalyst, effects of solvents, and the reaction time (Table 2). Firstly, the effect of catalyst loading was examined (entries $1-5)$. Subsequently, $5 \mathrm{~mol} \%$ of organocatalyst $\mathbf{4 f}$ showed the best catalytic activity and afforded the corresponding chiral Michael adduct 7a with good chemical yield with both excellent diastereoselectivity and enantioselectivity $(93 \%, d r$. 99:1, 98\% ee, entry 3).

Table 2. Optimization conditions of asymmetric Michael additions of $\beta$-keto esters $\mathbf{5 a , b}$ with trans- $\beta$-nitroolefin $\mathbf{6 a}$ using organocatalysts $\mathbf{4 f}$.

\begin{tabular}{|c|c|c|c|c|c|}
\hline \multicolumn{2}{|c|}{$\begin{array}{c}\mathbf{5 a}, \mathbf{b} \\
\text { (2.0 equiv.) }\end{array}$} & $\begin{array}{c}\mathbf{6 a} \\
\text { (1.0 equiv.) }\end{array}$ & $\begin{array}{l}\frac{\begin{array}{c}\text { catalyst } \mathbf{4 f} \\
(\mathrm{mol} \%)\end{array}}{\text { solvent }} \\
\text { r.t., } 48 \mathrm{~h}\end{array}$ & \multicolumn{2}{|c|}{$[2 R, 3 S]-7 \mathbf{a}, \mathbf{b}$} \\
\hline entry $^{a}$ & $\begin{array}{c}\text { catalyst } \mathbf{4 f} \\
(\mathrm{mol} \%)\end{array}$ & solvent & $\begin{array}{l}\text { yield } \\
(\%)^{b}\end{array}$ & $d r^{\mathrm{c}}$ & $\begin{array}{c}e e \\
(\%)^{\mathrm{d}}\end{array}$ \\
\hline 1 & 20 & $\mathrm{H}_{2} \mathrm{O}$ & 90 & $90: 10$ & 80 \\
\hline 2 & 10 & $\mathrm{H}_{2} \mathrm{O}$ & 91 & $98: 2$ & 84 \\
\hline 3 & 5 & $\mathrm{H}_{2} \mathrm{O}$ & 93 & $99: 1$ & 98 \\
\hline 4 & 2.5 & $\mathrm{H}_{2} \mathrm{O}$ & 46 & $90: 10$ & 91 \\
\hline 5 & 1 & $\mathrm{H}_{2} \mathrm{O}$ & 23 & $99: 1$ & 90 \\
\hline $6^{\mathrm{e}}$ & 5 & $\mathrm{H}_{2} \mathrm{O}$ & 74 & $96: 4$ & 94 \\
\hline 7 & 5 & toluene & 92 & $90: 10$ & 88 \\
\hline 8 & 5 & benzene & 64 & $81: 19$ & 62 \\
\hline 9 & 5 & hexane & 88 & $86: 14$ & 68 \\
\hline 10 & 5 & $\mathrm{CH}_{2} \mathrm{Cl}_{2}$ & 99 & $88: 12$ & 43 \\
\hline 11 & 5 & $\mathrm{CHCl}_{3}$ & 34 & $84: 16$ & 83 \\
\hline 12 & 5 & $\mathrm{Et}_{2} \mathrm{O}$ & 37 & $89: 11$ & 76 \\
\hline 13 & 5 & THF & 68 & $88: 12$ & 49 \\
\hline 14 & 5 & 1,4-dioxane & 89 & $80: 20$ & 51 \\
\hline 15 & 5 & EtOAc & 74 & $84: 16$ & 69 \\
\hline 16 & 5 & $\mathrm{MeOH}$ & 17 & $80: 20$ & 64 \\
\hline 17 & 5 & $\mathrm{DMF}$ & 37 & $77: 23$ & 90 \\
\hline 18 & 5 & DMSO & 89 & $80: 20$ & 51 \\
\hline 19 & 5 & $\mathrm{CH}_{3} \mathrm{CN}$ & 24 & $82: 18$ & 88 \\
\hline $20^{f}$ & 5 & $\mathrm{H}_{2} \mathrm{O}$ & 65 & $99: 1$ & 95 \\
\hline $21^{\mathrm{f}}$ & 5 & $\mathrm{H}_{2} \mathrm{O}$ & 57 & $99: 1$ & 92 \\
\hline
\end{tabular}

${ }^{a}$ The reactions were carried out under suspension. ${ }^{b}$ Isolated yields. ${ }^{\mathrm{c}}$ The diastereomeric ratio $(d r)$ was determined by ${ }^{1} \mathrm{H}$ NMR spectroscopy of the crude reaction mixture. ${ }^{\mathrm{d}}$ The ee values were determined by HPLC with a Daicel Chiralcel OD-H column. ${ }^{\mathrm{e}}$ The use of ethyl ester $\mathbf{5 b}$ in entry $6 .{ }^{\mathrm{f}}$ The reactions were carried out at $24 \mathrm{~h}$ and $12 \mathrm{~h}$, respectively.

Furthermore, the use of ethyl ester $\mathbf{5 b}$ also afforded the corresponding adduct $\mathbf{7 b}$ in good chemical yield and selectivities (74\%, $d r$. 96:4, 94\% ee, entry 6). Next, the Michael addition was examined in various solvents (entries 7-19) in the presence of $5 \mathrm{~mol} \%$ of $\mathbf{4 f}$ for $48 \mathrm{~h}$. Although all reactions proceeded in these solvents, but better results than the use of water were not obtained. Considering that the reaction using $\mathrm{H}_{2} \mathrm{O}$ was carried out under suspension, $\mathrm{H}_{2} \mathrm{O}$ might be work as an additive but a solvent, although the reasons are not clear. We also examined the effect of the reaction time period ( $24 \mathrm{~h}$ and $12 \mathrm{~h}$ ) in the presence of best $\mathrm{H}_{2} \mathrm{O}(24 \mathrm{~h}$ : entry 20, 12h: entry 21). However, the chemical yields and the enantioselectivities decreased than the result of $48 \mathrm{~h}$, although the reasons are not clear. Based on these results, it was proved that $5 \mathrm{~mol} \%$ of catalyst loading in the presence of $\mathrm{H}_{2} \mathrm{O}$ at $48 \mathrm{~h}$ was the best reaction conditions to obtain the chiral Michael adduct 7a in satisfactory chemical yield and stereoselectivities (entry 3 ).

After optimization of the reaction conditions, we examined the generality of superior catalyst $\mathbf{4 f}$ in the reactions of $\beta$-keto esters 5a,c-e with various trans- $\beta$-nitroolefins 6a-h (Scheme 3 ). All reactions proceeded to afford the corresponding chiral Michael adducts $\mathbf{7 c - l}$. The reactions of substrate 5a with $o$ - or $p$-methylated nitrostyrenes $\mathbf{6 b}, \mathbf{c}$ afforded the corresponding chiral Michael adducts $\mathbf{7 c , d}$ in good to moderate chemical yields, diastereoselectivities and good enantioselectivities (7c: 74\%, $d r .98: 2,98 \% e e, 7 \mathbf{d}: 91 \%, d r .93: 7,90 \% e e)$. The use of $p$-methoxynitrostyrene $\mathbf{6 d}$ afforded the corresponding adduct $7 \mathrm{e}$ in good chemical yield (86\%) and stereoselectivities $(d r$. 97:3, 90\% ee). Also, the reactions using the $p$-halogenated nitrostyrenes 6e,f was also in accordance with this condition and resulted in corresponding adducts $\mathbf{7 f}, \mathbf{g}$ were obtained with satisfactory results (7f: $81 \%, d r .94: 6,97 \% e e, 7 \mathbf{g}: 91 \%, d r$. $99: 1, \quad 92 \% \quad e e)$. The uses of both heterocyclic 2-furyl-nitroethylene $\mathbf{6 g}$ and nitrovinyl-thiophene $\mathbf{6 h}$ afforded the adducts $\mathbf{7 h}$ and $\mathbf{7} \mathbf{i}$, respectively, in good chemical yields (7h: $86 \%$, 7i: $79 \%$ ) with good stereoselectivities (7h: $d r .93: 7$, 93\% ee, 7i: $\quad d r . \quad 83: 17, \quad 91 \%$ ee). Furthermore, 1-oxo-2-indanecarboxylate $\mathbf{5 c}$ with $\mathbf{6 a}$ also afforded the corresponding adduct $\mathbf{7 j}$ in good chemical yield and enantioselectivity $(82 \%, 88 \%$ ee $)$ with good diastereoselectivity (dr. 85:15). Also, the uses of methyl 2-oxo-1-cyclohexanecarboxylate 5d and 2-oxo-1-cycloheptanecarboxylate 5 e also provided the corresponding adducts $\mathbf{7 k , \mathbf { l }}$ in good chemical yields and high level of stereoselectivities (7k: 76\%, $d r .90: 10,91 \%$ ee, $7 \mathbf{l}$ : $84 \%, d r .86: 14,88 \%$ ee). In addition, the reaction of acyclic methyl 2-methylacetoacetate, instead of cyclic $\beta$-keto esters, with 6a, was examined. However, only trace amount of the corresponding Michael adduct was conformed in this reaction condition, although the reason is not clear.

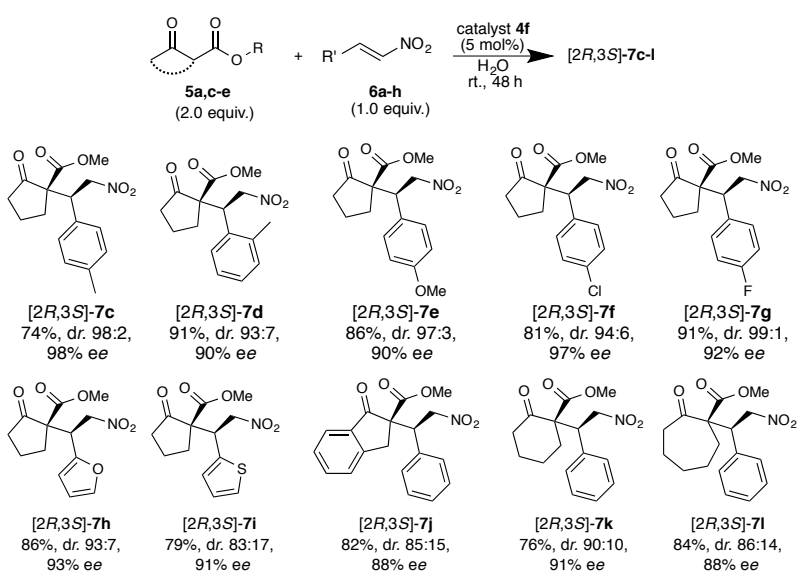


Scheme 3. Generality of catalyst $4 \mathbf{f}$ in asymmetric Michael additions of $\beta$-keto esters 5a,c-e with trans- $\beta$-nitroolefins $\mathbf{6 a - h}$.

In view of the excellent enantioselectivity $(98 \% e e)$ of the Michael adduct $[2 R, 3 S]-7 \mathbf{a}$ that was obtained in the reaction of 5a with 6a using catalyst $\mathbf{4 f}$, the results of its calculation studies (Fig. 1-3), and based on the structure of catalyst 4 a by our previous study, ${ }^{8}$ an enantioselective reaction course is proposed as follows (Scheme 4).

For the estimation of enantioselective reaction course, the conformational analysis by using the scan of total energies for 4f was firstly carried out and the result was indicated that the conformation of I-1 was most stable as the conformation of $\mathbf{4 f}$ (Fig. 1).

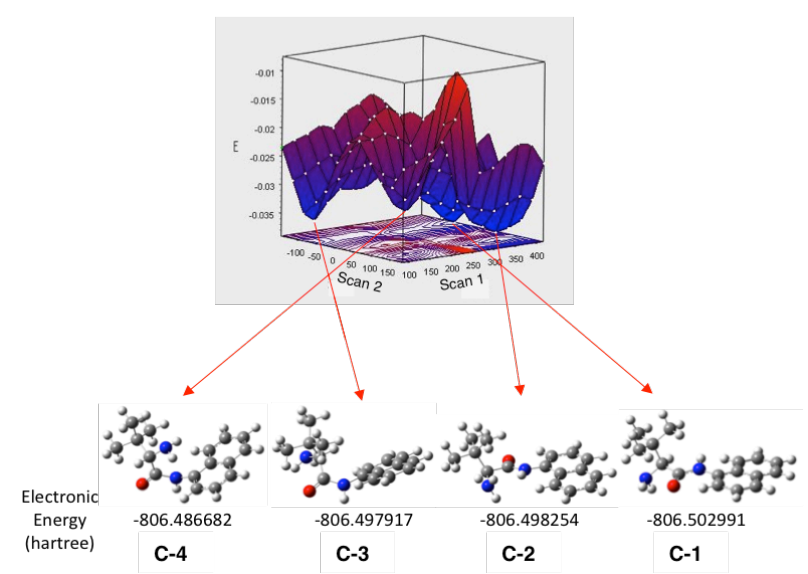

Figure 1. The scan of total energies for $\mathbf{4 f}$ (conformations $\mathbf{C - 1}$ to $\mathbf{C}-4$ generated).

Furthermore, to examine the regioselectivity of the reaction between 5a and 6a more accurately, the calculation of the energies and coefficients of their frontier orbitals was conducted. The energy levels of the orbitals clearly showed the dominate the interaction between the LUMO of $\mathbf{6 a}$ and the

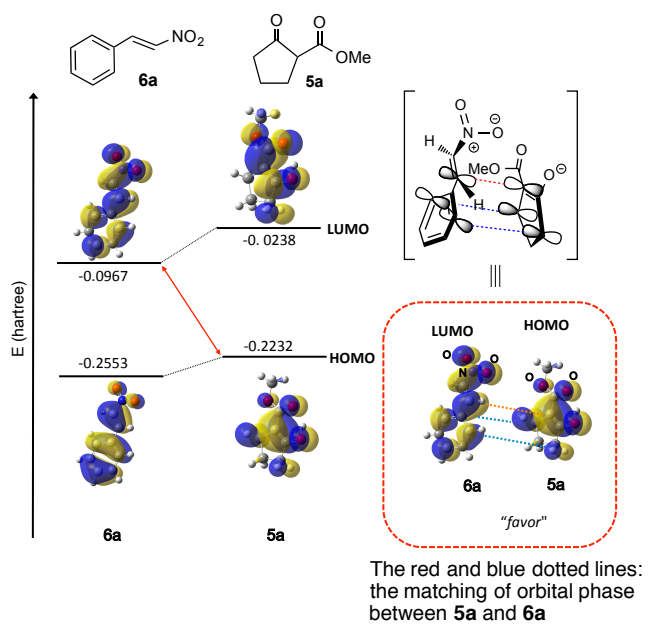

Figure 2. The frontier orbitals between $5 \mathbf{a}$ and $\mathbf{6 a}$ obtained by DFT calculations at the 6-31 G(d) level using a B3LYP exchange-correction functional [the dotted lines (blue and red) in the red square indicated an interactions between the molecular orbitals of $\mathbf{6 a}$ and $\mathbf{5 a}$ ].

HOMO of $\mathbf{5 a}$, and their orbital phase and the coefficient of the orbital clearly demonstrated a matching in favor of overlapping to afford the observed configuration of major adduct 7a (Fig. 2).
In addition, the positive charge was on the nitrogen atom of the amino moiety in the catalyst $\mathbf{4 f}(\mathbf{C}-\mathbf{1})$, and the negative charges were both on the oxygen atoms of the nitro group in nitrostyrene $\mathbf{6 a}$ and on the oxygen atoms of the $\beta$-keto ester $\mathbf{5 a}$ (Fig. 3).

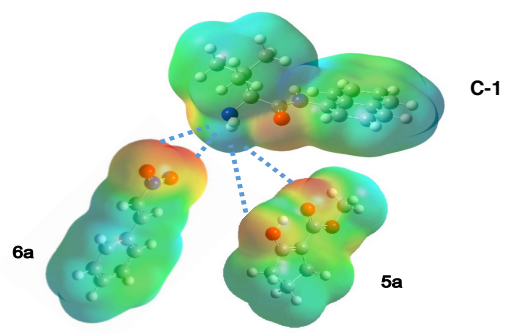

Figure 3. The electrostatic potential maps of $\mathbf{4 f}(\mathbf{C}-\mathbf{1}), \mathbf{5 a}$ and $6 a$.

Moreover, we examined the reaction of amino amide $\mathbf{4 f}$, that acts as the best catalyst, with $\beta$-keto methyl ester under the same reaction condition in Table 1 . However, the formation of enamine species was not observed in this reaction condition. This result indicates that amino amide $\mathbf{4 f}$ may act as a basic catalyst in this reaction.

Based on the calculation results of the scan total energy, the structure of catalyst $\mathbf{4 f}$ might be fixed by the intramolecular hydrogen bonding interaction between the amino hydrogen atom and the amide oxygen atom, and thereby catalyst $\mathbf{4}$ f might have the conformation shape $\mathbf{C - 1}$ of which are having less steric interaction between the tert-butyl substituent at the $\alpha$-position and the 1-naphthy substituent on amide group. Furthermore, when the reaction proceeds, $\mathbf{4 a}$ acts as a base and then it might be formed Ts-1-4 in which both substrates $\mathbf{5 a}$ and 6a fixed with the ammonium hydrogen atom on the ammonium catalyst species by the hydrogen bonding interactions. In the proposed Ts-1-4, the reaction might be proceeding through Ts-1, based on the frontier and the electrostatic potential map, that has a smaller steric interaction both between substrates $\mathbf{5 a}$ and $\mathbf{6 a}$ and between $\mathbf{4 f}$ and the 1-naphthyl substituent at amide group on the ammonium catalyst species than those of Ts-2-4 that have a larger steric interaction between substrates $\mathbf{5 a}, \mathbf{6 a}$ and the 1-naphthyl substituent ammonium catalyst species.

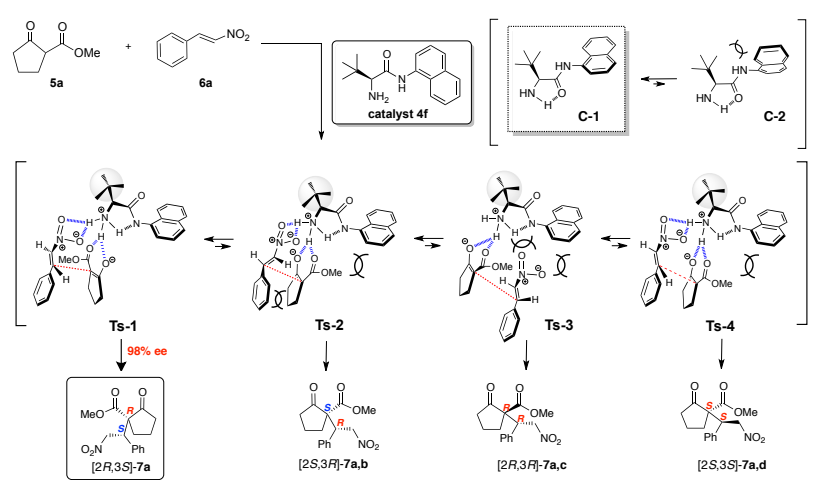

Scheme 4. Plausible reaction course using catalyst $4 \mathbf{f}$ (the blue dotted lines indicated the hydrogen bonds among the $\mathrm{N}^{+} \mathrm{H}$ moiety of $\mathbf{4 f}, \mathbf{6 a}$ and $\mathbf{5 a}$. The red dotted lines indicated the interactions between the molecular orbitals of $\mathbf{6 a}$ and $\mathbf{5 a}$ ).

\section{Conclusion}

In conclusion, the new simple amino amide organocatalysts 4a-i were developed and examined based on a new catalyst design concept in the asymmetric Michael addition of various $\beta$-keto esters 5a-e with trans- $\beta$-nitroolefins 6a-h. Among the 
optimized catalysts 4a-i, the catalyst 4 ff possessing with 1-naphthyl group have showed a best catalytic activity in this reaction and afforded the corresponding chiral Michael adducts 7a-l having quaternary chiral carbon centre with good to excellent chemical yields (up to 99\%), diastereoselectivities (up to 99:1) and enantioselectivities (up to $98 \%$ ee). The modification of amino amide catalysts and detailed mechanistic study are in progress.

\section{Acknowledgement}

We thank Adaptable \& Seamless Technology Transfer Program through Target-driven R\&D from Japan Science and Technology Agency (JST) and Muroran Institute of Technology for partial financial support to this study.

\section{Supporting Information}

Supplementary data related to this article can be found at ---------.

\section{References}

1. a) P. Wadhwa, A. Kharbanda, A. Sharma, Asian J. Org. Chem. 2018, 7, 634-661.

b) D. Sakamoto, Y. Hayashi, Chem. Lett. 2018, 47, 833835.

c) D. Uraguchi, Y. Kawai, H. Sasaki, K. Yamada, T. Ooi, Chem. Lett. 2018, 47, 594-597.

d) D. R. Ñíguez, G. Guillena, A. Diago, ACS Sustainable Chem. Eng. 2017, 5, 10649-10656.

e) J. T. Menezes Correia, B. List, F. Coelho, Angew. Chem. Int. Ed. 2017, 56, 7967-7970.

f) R. Navarro, C. Monterde, S. Molina, M. Pérez-Perrino, F. Reviriego, A. del Prado, A. Gallardo, H. Reinecke, RSC Adv. 2017, 7, 56157-56165.

g) S. Matsuoka, Y. Hoshiyama, K. Tsuchimoto, M. Suzuki, Chem. Lett. 2017, 46, 1718-1720.

h) N. G. Schmidt, E. Eger, W. Kroutil, ACS Catal. 2016, 6, 4286-4311.

i) T. Ling, F. Rivas, Tetrahedron 2016, 43, 6729-6777.

h) C. R. Müller, A. Rosen, P. D. de María, ACS Sustainable Chem. Proc. 2015, 3, 1-12.

j) X. Gu, Y. Dai, T. Guo, A. Franchino, D. J. Dixon, J. Ye, Org. Lett. 2015, 17, 1505-1508.

k) S. Kawazoe, K. Yoshida, Y. Shimazaki, T. Oriyama, Chem. Lett. 2014, 43, 1659-1661.

1) K. C. Nicolaou, Angew. Chem. Int. Ed. 2013, 52, 131146.

m) K. Patora-Komisarska, M. Benohoud, H. shikawa, D. Seebach, Y. Hayashi, Helv. Chim. Acta 2011, 94, 719745.

n) G. Imanzadeh, F. Ahmadi, M. Zamanloo, Y. Mansoori, Molecules 2010, 15, 7353-7362.

o) R. Ballini, A. Palmieri, P. Righi, Tetrahedron 2007, 63, 12099-12121.

p) E. Lewandowska, E. Tetrahedron 2007, 10, 21072122 .

q) D. Enders, A. Saint-Dizier, M. I. Lannou, A. Lenzen, Eur. J. Org. Chem. 2006, 1, 29-49.

r) E. Reyes, J. L. Vicario, L. Carrillo, Org. Lett. 2006, 8, 6135-6138.

s) O. M. Berner, L. Tedeschi, D. Enders, Eur. J. Org. Chem. 2002, 12, 1877-1894.

t) A. Alexakis, O. Andrey, Org. Lett. 2002, 4, 36113614 .

u) H. Kotsuki, K. Arimura, T. Ohishi, R. J. Maruzasa, J. Org. Chem. 1999, 64, 3770-3773.

2. a) Y. Chen, P. Sun, T. Li, Y. Zou, Y. Huang, Y. Shen, Tetrahedron Lett. 2018, 59, 2399-2402. b) C. Hui, F. Pu, J. Xu, Chem. Eur. J. 2016, 22, 1-15. c) L-R. Zhong, Z-J. Yao, Sci. Chin. Chem. 2016, 59, 1079-1087.

d) J. Hu, M. Bian, H. Ding, Tetrahedron Lett. 2016, 57, 5519-5539.

e) S. B. Bhorkade, K. B. Gavhane, Tetrahedron Lett. 2016, 57, 2575-2578.

f) T. Shibata, T. Shizuno, T. Sasaki, Chem. Commun. 2015, 51, 7802-7804.

g) K. Brak, E. N. Jacobsen, Angew. Chem. Int. Ed. 2013, 52, 534-561.

h) J. G. Hernández, E. Juaristi, Chem. Commun. 2012, 48, 5396-5409.

i) L. Zhao, J. Shen, D. Liu, Y. Liu, W. Zhang, Org. Biomol. Chem. 2012, 10, 2840-2846.

j) S. B. Woo, D. Y. Kim, Beilstein J. Org. Chem. 2012, 8 , 699-704.

k) H. Li, L. Zu, L. Xie, J. Wang, W. Jiang, W. Wang, Org. Lett. 2007, 9, 1833-1835.

1) P. Melchiorre, M. Marigo, A. Carlone, G. Bartoli, Angew. Chem. Int. Ed. 2008, 47, 6138-6171.

m) A. Alexakis, S. March, J. Org. Chem. 2002, 67, 8753-8757.

3. a) D. Bécart, V. Diemer, A. Salaün, M. Oiarbide, Y. R. Nelli, B. Kauffmann, L. Fischer, C. Palomo, G. Guichard, J. Am. Chem. Soc., 2017, 139, 12524-12532.

b) C. G. Avila-Ortiz, L. Díaz-Corona, E. Jiménez-González, E. Juaristi, Molecules 2017, 22, 1328 1341.

c) M. Furutachi, Z. Chen, S. Matsunaga, M. Shibasaki, molecules 2010, 15, 532-544.

d) J. Luo, L. W. Xu, R. A. S. Hay, Y. Lu, Org. Lett. 2009, 11, 437-440.

e) X. Jiang, Y. Zhang, X. Liu, G. Zhang, L. Lai, Wu, J. Zhang, R. Wang, J. Org. Chem. 2009, 74, 5562-5567.

f) D. Almasi, D. A. Alonso, E. Gómez-Bengoa, C. Nájera, J. Org. Chem. 2009, 74, 6163-6168.

g) J. P. Malerich, K. Hagihara, V. H. Rawal, J. Am. Chem. Soc. 2008, 130, 14416-14417.

h) J. Christoffers, G. Koripelly, A. Rosiak, M. Rössle, Synthesis 2007, 1279-1300.

i) M. Watanabe, A. Ikagawa, H. Wang, K. Murata, T. Ikariya, J. Am. Chem. Soc. 2004, 126, 11148-11149.

j) Y. Hayashi, H. Gotoh, T. Hayashi, M. Shoji, Angew. Chem. Int. Ed. 2005, 44, 4212-4215.

k) D. Gryko, R. Lipiñski, Adv. Synth. Catal. 2005, 347, 1948-1952.

1) H. Li, Y. Wang, L. Tang, F. Wu, X. Liu, C. Guo, B. M. Foxman, L. Deng, Angew. Chem. Int. Ed. 2005, 44, 105108.

m) R. B. Grossman, S. Comesse, R. M. Rasne, K. Hattori, M. N. Delong, J. Org. Chem. 2003, 68, 871-874.

n) B. List, P. Pojarliev, H. J. Martin, Org. Lett. 2001, 3, 2423-242.

4. a) K. Masuda, T. Ichitsuka, N. Koumura, K. Sato, S. Kobayashi, Tetrahedron 2018, 74, 1705-1730.

b) Y. N. Gao, M. Shi, Chin. Chem. Lett. 2017, 28, 493502.

c) B. Watanabe, T. Morikita, Y. Tabuchi, R. Kobayashi, C. Li, M. Yamamoto, T. Koeduka, J. Hiratake, Tetrahedron Lett. 2017, 58, 3700-3703.

d) L. Tian, Y. C. Luo, X. Q. Hu, P. F. Xu, Asian J. Org. Chem. 2016, 5, 580-607.

e) Y. Liu, S. J. Han, W. B. Liu, B. M. Stoltz, Acc. Chem. Res. 2015, 48, 740-751.

f) Y. Xiao, Z. Sun, H. Guo, O. Kwon, O. Beilstein J. Org. 
Chem. 2014, 10, 2089-2121.

g) Z. Yu, X. Liu, L. Zhou, L. Lin, X. Feng, Angew. Chem., Int. Ed. 2009, 48, 5195-5198.

h) J. P. Malerich, K. Hagihara, V. H. Rawal, J. Am. Chem. Soc. 2008, 130, 14416-14417.

i) Z. H. Zhang, X. Q. Dong, D. Chen, C. J. Wang, Chem. Eur. J. 2008, 14, 8780-8783.

j) D. A. Evans, S. Mito, D. Seidel, J. Am. Chem. Soc. 2007, 129, 11583-11592.

j) B. D. Mather, K. Viswanathan, K. M. Miller, T. E. Long, Prog. Polym. Sci. 2006, 31, 487-531.

k) T. Okino, Y. Hoashi, T. Furukawa, X. Xu, Y. Takemoto, J. Am. Chem. Soc. 2005, 127, 119-125.

1) H. Li, Y. Wang, L. Tang, F. Wu, X. Liu, C. Guo, Angew. Chem. Int. Ed. 2004, 44, 105-108.

m) T. Okino, Y. Hoashi, Y. Takemoto, J. Am. Chem. Soc. 2003, 125, 12672-12673.

n) M. S. Taylor, E. N. Jacobsen, J. Am. Chem. Soc. 2003, 125, 11204-11205.

o) G. Zhu, Z. Chen, Q. Jiang, D. Xiao, P. Cao, X. Zhang, J. Am. Chem. Soc. 1997, 119, 3836-3837.

5. a) Y. Yao, Y. Liu, L. Ye, F. Chen, X. Li, Z. Zhao, Tetrahedron 2017, 73, 2311-2315.

b) S. Liu, Q. Wang, L. Ye, Z. Shi, Z. Zhao, X. Yang, K. Ding, X. Li, Tetrahedron 2016, 72, 5115-5120.

c) L. Androvič, P. Drabina, M. Svobodová, M. Sedlák, Tetrahedron: Asymmetry 2016, 27, 782-787.

d) Q. Wang, J. Gong, Y. Liu, Y. Wang, Z. Zhou, Tetrahedron 2014, 70, 8168-8173.

e) H. Kilic, S. Bayindir, E. Erdogan, N. Saracoglu, Tetrahedron 2012, 68, 5619-5630.

f) Z. Ma, Y. Liu, P. Li, H. Ren, Y. Zhu, J. Tao, Tetrahedron: Asymmetry 2011, 22, 1740-1748.

g) C. F. Nising, S. Bräse, Chem. Soc. Rev. 2008, 37, 1218-1228.

h) D. A. Alonso, C. Nájera, Tetrahedron: Asymmetry 2007, 18, 299-365.

i) S. B. Tsogoeva, Eur. J. Org. Chem. 2007, 11, 17011716.

j) S. Sulzer-Mossé, A. Alexakis, Chem. Commun. 2007, 30, 3123-3135.

k) L. W. Xu, C. G. Xia, Eur. J. Org. Chem. 2005, 4, 633639.

1) O. M. Berner, L. Tedeschi, D. Enders, Eur. J. Org. Chem. 2002, 12, 1877-1894.

m) N. Krause, A. Hoffmann-Röder, Synthesis 2001, 2, 171-196.

n) J. Christoffers, Eur. J. Org. Chem. 1998, 7, 12591266.

6. a) M. Chennapuram, I. A. Owolabi, C. Seki, Y. Okuyama, E. Kwon, K. Uwai, M. Tokiwa, M. Takeshita, H. Nakano, ACS Omega, 2018, 3, 11718-11726.

b) H. Nakano, I. A. Owolabi, M. Chennapuram, C. Seki, Y. Okuyama, E. Kwon, K. Uwai, M. Tokiwa, M. Takeshita, Heterocycles. 2018, DOI: 10.3987/REV-18-SR(T)3.

c) U. V. Subba Reddy, M. Chennapuram, K. Seki, C. Seki, B. Anusha, E. Kwon, Y. Okuyama, K. Uwai, M. Tokiwa, M. Takeshita, H. Nakano, Eur. J. Org. Chem. 2017, 26, 3874-3885.

d) A. Ogasawara, U. V. Subba Reddy, C. Seki, Y. Okuyama, K. Uwai, M. Tokiwa, M. Takeshita M, H. Nakano, Tetrahedron: Asymmetry 2016, 27, 1062-1068.

e) T. Takahasi, U. V. Subba Reddy, Y. Kohari, C. Seki, T. Furuyama, N. Kobayashi N, Y. Okuyama, E. Kwon, K. Uwai, M. Tokiwa, M. Takeshita, H. Nakano, Tetrahedron
Lett. 2016, 57, 57771-5776.

f) J. Kumagai, T. Otsuki, U. V. Subba Reddy, Y. Kohari, C. Seki, K. Uwai, Y. Okuyama, E. Kwon, M. Tokiwa, M. Takeshita, H. Nakano, Tetrahedron: Asymmetry 2015, 26, 1423-1439.

g) T. Otsuki, J. Kumagai, Y. Kohari, Y. Okuyama, E. Kwon, C. Seki, K. Uwai, Y. Mawatari, N. Kobayashi, T. Iwasa, M. Tokiwa, M. Takeshita, A. Maeda, A. Hashimoto, K. Turuga, H. Nakano, Eur. J. Org. Chem. 2015, 7292-7300.

h) Y. Kohari, Y. Okuyama, E. Kwon, T. Furuyama, N. Kobayashi, T. Otuki, J. Kumagai, C. Seki, K. Uwai, G. Dai, T. Iwasa, H. Nakano, J. Org. Chem. 2014, 79, 95009511.

i) Y. Sakuta, Y. Kohari, K. Hutabarat, K. Uwai, E. Kwon, Y. Okuyama, C. Seki, H. Matsuyama, N. Takano, M. Tokiwa, M. Takeshita, H. Nakano, Heterocycles 2012, 86, 1379-1389.

j) C. Suttibut, Y. Kohari, K. Igarashi, H. Nakano, M. Hirama, C. Seki, H. Matsuyama, K. Uwai, N. Takano, Y. Okuyama, K. Osone, M. Takeshita, E. Kwon, Tetrahedron Lett. 2011, 52, 4745-4748.

k) H. Nakano, K. Osone, M. Takeshita, E. Kwon, C. Seki, M. Matsuyama, N. Takano, Y. Kohari, Chem. Commun. 2010, 46, 4827-4829.

7. J. Kimura, U. V. Subba Reddy, Y. Kohari, C. Seki, Y. Mawatari, K. Uwai, Y. Okuyama, E. Kwon, M. Tokiwa, M. Takeshita, T. Iwasa, H. Nakano, Eur. J. Org. Chem. 2016, 22, 3748-3756.

8. I. A. Owolabi, U. V. Subba Reddy, M. Chennapuram, C. Seki, Y. Okuyama, E. Kwon, K. Uwai, M. Tokiwa, M. Takeshita, H. Nakano, Tetrahedron 2018, 74, 4705-4711.

9. a) M. S. Ullah, S. Itsuno, Mol. Catal. 2017, 438, 239-244. b) Z. Zhou, Y. Li, B. Han.; L. Gong.; E. Meggers, Chem. Sci. 2017, 8, 5757-5763.

c) M. Bera, T. K. Ghosh, B. Akhuli, P. Ghosh, J. Mol. Catal. Chem. 2015, 408, 287-295.

d) P. Vinayagam, M. Vishwanath, V. Kesavan, V. Tetrahedron: Asymmetry 2014, 25, 568-577.

e) R. C. da Silva, G. P. da Silva, D. P. Sangi, J. G. de M. Pontes, A. G. Ferreira, A. G. Corrêa, M. W. Paixão, Tetrahedron 2013, 69, 9007-9012.

f) T. Nemoto, K. Obuchi, S. Tamura, T. Fukuyama, Y. Hamada, Tetrahedron Lett. 2011, 52, 987-991.

g) R. Manzano, J. M. Andrés, M. D. Muruzábal, R. Pedrosa, Adv. Synth. Catal. 2010, 352, 3364-3372.

h) Z. H. Zhang, X. Q. Dong, D. Chen, C. J. Wang, Chem. Eur. J. 2008, 14, 8780-8783.

i) T. Okino, Y. Hoashi, T. Furukawa, X. Xu, Y. Takemoto, J. Am. Chem. Soc. 2005, 127, 119-125. 


\section{Graphical Abstract}

\section{Amino Amide Organocatalysts for Asymmetric Michael Addition of $\beta$-keto Esters with $\beta$-Nitroolefins}

Isiaka Alade Owolabi, ${ }^{1}$ Madhu Chennapuram, ${ }^{1}$ Chigusa Seki, ${ }^{1}$ Yuko Okuyama, ${ }^{2}$ Eunsang Kwon, ${ }^{* 3}$ Koji Uwai, ${ }^{1}$ Michio Tokiwa, ${ }^{4}$ Mitsuhiro Takeshita, ${ }^{4}$ and Hiroto Nakano ${ }^{* 1}$

The catalytic activities of a new simple amino amide organocatalysts A were developed and examined based on a new catalyst design concept in the asymmetric Michael addition of various $\beta$-keto esters B with trans- $\beta$-nitroolefins $\mathbf{C}$. Among the optimized catalysts, the catalyst A possessing with 1-naphthyl group showed best catalytic performance and afforded the corresponding chiral Michael adducts $\mathbf{D}$ in a both good to excellent chemical yields (up to $99 \%$ ) and stereoselectivities (up to $d r$. 99:1, up to $98 \%$ ee).
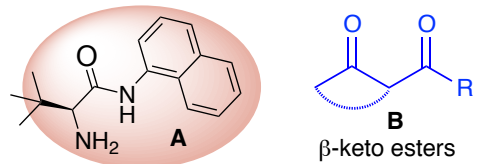

$\beta$-keto esters

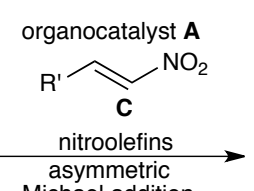

asymmetric

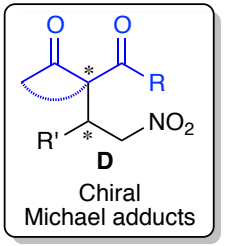

up to $99 \%$, up to $d r$ : $99: 1$

up to $98 \%$ ee 